\title{
Advanced glycation end-products affect the cytoskeletal structure of rat glomerular endothelial cells via the Ras-related C3 botulinum toxin substrate 1 signaling pathway
}

\author{
LEI LAN ${ }^{1,2}$ YONGSHENG HAN ${ }^{3}$, WEI REN ${ }^{2}$, JIELONG JIANG ${ }^{2}$, PENG WANG $^{2}$ and ZHAO HU ${ }^{1}$ \\ ${ }^{1}$ Department of Nephrology, Affiliated Qilu Hospital, Shandong University, Jinan, Shandong 250012; \\ Departments of ${ }^{2}$ Nephrology and ${ }^{3}$ Emergency Internal Medicine, Affiliated Anhui Provincial Hospital, \\ Anhui Medical University, Hefei, Anhui 230001, P.R. China
}

Received May 19, 2014; Accepted December 9, 2014

DOI: $10.3892 / \mathrm{mmr} .2015 .3317$

\begin{abstract}
The present study aimed to determine the molecular mechanisms leading to the production of advanced glycation end-products (AGEs) and their effect on the morphology and function of rat glomerular capillary endothelial cells (GECs). Primary rat GECs were treated with AGE-modified human serum albumin (AGE-HSA) and divided into groups according to AGE concentration and treatment time. The structure and distribution of cytoskeletal protein F-actin and the cortical actin binding protein, cortactin, were analyzed using immunofluorescence and confocal microscopy. As the Ras-related C3 botulinum toxin substrate 1 (Rac1) signaling pathway was previously identified to be involved in mediating the contraction of endothelial actin-myosin activity, Rac1 was examined subsequent to treatment of the cells with the Racl agonist 2'-O-methyladenosine-3',5'-cyclic monophosphate (O-Me-cAMP) for $1 \mathrm{~h}$ using a pull-down assay. Cell permeability was determined by the leakage rate of a fluorescein isothiocyanate fluorescent marker protein. AGE-HSA treatment resulted in alterations in the structure and distribution of F-actin and cortactin in a dose- and time-dependent manner, while no effect was observed with HSA alone. The effect of AGE on the cytoskeleton was inhibited by the addition of O-Me-cAMP. AGE-HSA significantly reduced the level of Racl activity $(\mathrm{P}<0.05)$; however, no effect was observed on total protein levels. Furthermore, AGE-HSA treatment led to a significant increase in the permeability of endothelial cells $(\mathrm{P}<0.01)$, which was inhibited by $\mathrm{O}-\mathrm{Me}-\mathrm{cAMP}(\mathrm{P}<0.01)$. The Racl signaling
\end{abstract}

Correspondence to: Dr Zhao Hu, Department of Nephrology, Affiliated Qilu Hospital, Shandong University, 170 Wenhua West Road, Jinan, Shandong 250012, P.R. China

E-mail: zhaohu1234@yeah.net

Key words: advanced glycation end-products, Ras-related C3 botulinum toxin substrate 1 signaling pathway, glomerular endothelial cells, cytoskeletal actin, cortical actin binding protein pathway is thus suggested to serve an important function in mediating AGE-induced alterations in GEC morphology and function.

\section{Introduction}

Previous studies have demonstrated that an increase in glomerular capillary permeability is a key step leading to proteinuria in patients with diabetes and nephropathy (1). Glomerular capillary endothelial cells (GECs) constitute the first barrier preventing blood macromolecules, such as proteins, from passing through the endothelial wall (2-4). Therefore, the structure and distribution of GECs is closely associated with the permeability of the capillary. Previous studies have suggested that the reorganization and redistribution of the cytoskeleton protein F-actin and the cortical actin binding protein cortactin in endothelial cells is crucial to the increase in capillary permeability observed (5-7). In addition, the Ras-related $\mathrm{C} 3$ botulinum toxin substrate 1 (Rac1) signaling pathway has been identified to be involved in mediating the contraction of endothelial actin-myosin. This induces an alteration in cell morphology, destroying the cell-cell connections and forming the gap between cells (8-12), suggesting an association between the Rac1 signaling pathway and capillary permeability. It has been reported that advanced glycation end-products (AGEs) are involved in inducing alterations in the distribution of cytoskeletal proteins and endothelial cell permeability in diabetic patients with microvascular complications (13-16). However, the function of the Rac1 signaling pathway in this process remains elusive. In the present study, immunofluorescence staining and confocal microscopic analysis were conducted in order to determine the effect of AGEs on the structure and distribution of F-actin and cortactin in GECs. In addition, the levels of Racl activity were investigated using a pull-down assay, endothelial permeability was analyzed using a Transwell assay and the potential involvement of the Rac1 signaling pathway in this process was examined. The present study aimed to improve the understanding of the pathogenesis of nephropathic proteinuria in diabetics and provide novel therapeutic targets for diabetes and nephropathy. 


\section{Materials and methods}

Materials. Dulbecco's modified Eagle's medium, MCDB131, trypsin and fetal bovine serum (FBS) were purchased from Gibco Life Technologies (Carlsbad, CA, USA). Vascular endothelial growth factor was purchased from BD Biosciences (San Jose, CA, USA) and fluorescein isothiocyanate (FITC)-phalloidin was obtained from Molecular Probes Life Technologies (Grand Island, NY, USA). FITC-labeled goat anti-rabbit antibody, human serum albumin (HSA) and FITC-bovine serum albumin were from Sigma-Aldrich (St. Louis, MO, USA). DAPI was purchased from Invitrogen Life Technologies (Carlsbad, CA, USA) and 2'-O-methyladenosine-3',5'-cyclic monophosphate (O-Me-cAMP) was purchased from Aladdin Reagents Co., Ltd (Shanghai, China). Transwell was purchased from Corning Life Sciences (Tewksbury, MA, USA) and a Rac1 Activity Detection kit was purchased from EMD Millipore (Billerica, MA, USA). A Bradford kit was purchased from Shenneng Bocai Biotechnology Co., Ltd. (Shanghai, China).

Isolation and culture of GECs. The isolation and culture of primary GECs was conducted as previously described (17-19). All studies were approved by the Ethics Committee of Anhui Provincial Hospital (Hefei, China) for Animal Experiments and conformed to the Guide for the Care and Use of Laboratory Animals by the National Institutes of Health. Primary GECs were isolated from the kidneys of two male Wistar rats (body weight, 80-120 g) (Animal Department of Anhui Medical University, China; certificate no. 003). Primary GECs were cultured in MCDB131 medium supplemented with 10\% FBS in a humidified atmosphere with $5 \% \mathrm{CO}_{2}$. All operations were performed under $10 \%$ chloral hydrate (Hechang Chemical Company, Wuhan, China) and all efforts were made to minimize suffering.

Preparation of AGE-modified HSA. AGE-HSA was prepared by incubating HSA with glucose, as previously described (20-23). The reaction system contained $1.5 \mathrm{~g}$ HSA and $3.0 \mathrm{~g}$ D-glucose (Meilun Bio, Dalian, China), which were dissolved in $10 \mathrm{ml}$ phosphate-buffered saline (PBS; $0.2 \mathrm{~mol}$; pH 7.4; Gibco Life Technologies) and filtered with $0.22 \mu \mathrm{m}$ microporous membranes (EMD Millipore). The solution was then maintained in a container filled with nitrogen, which was sealed, protected from light and incubated at $37^{\circ} \mathrm{C}$ for three months. The unbound materials were removed using a dialysis bag (molecular weight, 10,000; Corning, Inc., Corning, NY, USA). The same procedure was completed without the addition of D-glucose for the control. The AGE value of the samples $(1 \mathrm{mg} / \mathrm{ml})$ was detected by fluorescence scanning (BX43; Olympus Corp., Tokyo, Japan) and samples were stored at $-20^{\circ} \mathrm{C}$.

Immunofluorescence staining. Staining was conducted as previously described (24-27). The slides were washed in PBS twice and fixed in $4 \%$ paraformaldehyde at room temperature for $30 \mathrm{~min}$. Subsequently, the slides were treated with $0.1 \%$ Triton X-100 (Sangon Biotech Co., Ltd, Shanghai, China) for 15 min (F-actin staining). Subsequent to blocking with $1 \%$ bovine serum albumin (BSA; Sigma-Aldrich) for
$1 \mathrm{~h}$ at room temperature, the samples were incubated with FITC-phalloidin for $1 \mathrm{~h}$ at room temperature in the dark (F-actin staining), or with rabbit anti-mouse monoclonal cortactin antibody (SAB1305513; 1:100) overnight at $4^{\circ} \mathrm{C}$. For cortactin staining, samples were then incubated with DyLight 605-labeled goat anti-rabbit antibody (SAB4600398; 1:500) for $1 \mathrm{~h}$ at room temperature in the dark following washing three times with PBS for 5 min. Antibodies were obtained from Santa Cruz Biotechnology, Inc. (Beijing, China) and samples were incubated with antibodies for $2 \mathrm{~h}$ at room temperature. Glycerol (50\%; Xilong Chemical Company, Guangzhou, China) was used to mount the glass slides with cells, and the images were captured using a confocal microscope.

Racl activity analysis. Racl activity was analyzed using a pull-down assay, as previously described $(9,28)$. The protein was extracted using a chemical cleavage method, and the protein concentration was detected using the Bradford assay. Samples $(50 \mu \mathrm{g})$ underwent SDS-PAGE (10\%) and were subsequently transferred to polyvinylidene difluoride membranes (EMD Millipore). The membranes were incubated with RAC1-GTP antibody and were then incubated with horseradish peroxidase-conjugated secondary antibodies (Zhongshan Jinqiao Company, Beijing, China). The chemiluminescent images were obtained using a Kodak Image Station 2000R system (Kodak, Rochester, NY, USA) and the results were analyzed using ImageJ software version $1.44 \mathrm{e}$ (National Institutes of Health, Bethesda, MD, USA).

Cell permeability analysis. Using a previously reported method (29), GECs were seeded into the top compartment of a Transwell chamber with FITC-albumin $(100 \mu 1 ; 1 \mathrm{mg} / \mathrm{ml}$; Sigma-Aldrich). Subsequent to incubation, the fluorescence intensity of samples was analyzed using a HTS-7000 Bio Assay Reader (BioAssay Systems, Hayward, CA, USA) with $495 \mathrm{~nm}$ excitation and $520 \mathrm{~nm}$ emission filters. The apparent permeability coefficient $\left[\left(\mathrm{P}_{\mathrm{a}}\right)=(\mathrm{F} / \mathrm{t})(1 / \mathrm{A})(\mathrm{v} / \mathrm{L})\right]$ was used, where $\mathrm{F}$ indicates the fluorescence intensity in the bottom chamber, $\mathrm{t}$ indicates time ( $\mathrm{sec}), \mathrm{A}$ is the membrane area $\left(\mathrm{cm}^{2}\right), \mathrm{v}$ is the solution volume in the bottom chamber and L indicates the fluorescence intensity in the top chamber. The results are expressed as a percentage $\left[\mathrm{P}_{\mathrm{a}} \%=\right.$ (experimental $\mathrm{P}_{\mathrm{a}}$ value/control $\mathrm{P}_{\mathrm{a}}$ value) $\left.x 100 \%\right]$. The experiments were repeated a minimum of five times.

Statistical analysis. Statistical analysis was performed using SPSS software, version 13.0 (SPSS, Inc., Chicago, IL, USA). All data are presented as the mean \pm standard error and were analyzed by a one-way analysis of variance. $\mathrm{P}<0.05$ was considered to indicate a statistically significant difference.

\section{Results}

Effect of AGE-HSA on F-actin and cortactin morphologies in GECs. Under normal conditions, endothelial cells appear smooth and intact (30). F-actin is filamentous among the long axis and near cell junctions and is present in reticular, intact and continuous lines, predominantly in the edges of cells and the inner membranes. A small amount of reticular nuclear matrix is also present around the nucleus. Cortactin is predominantly 


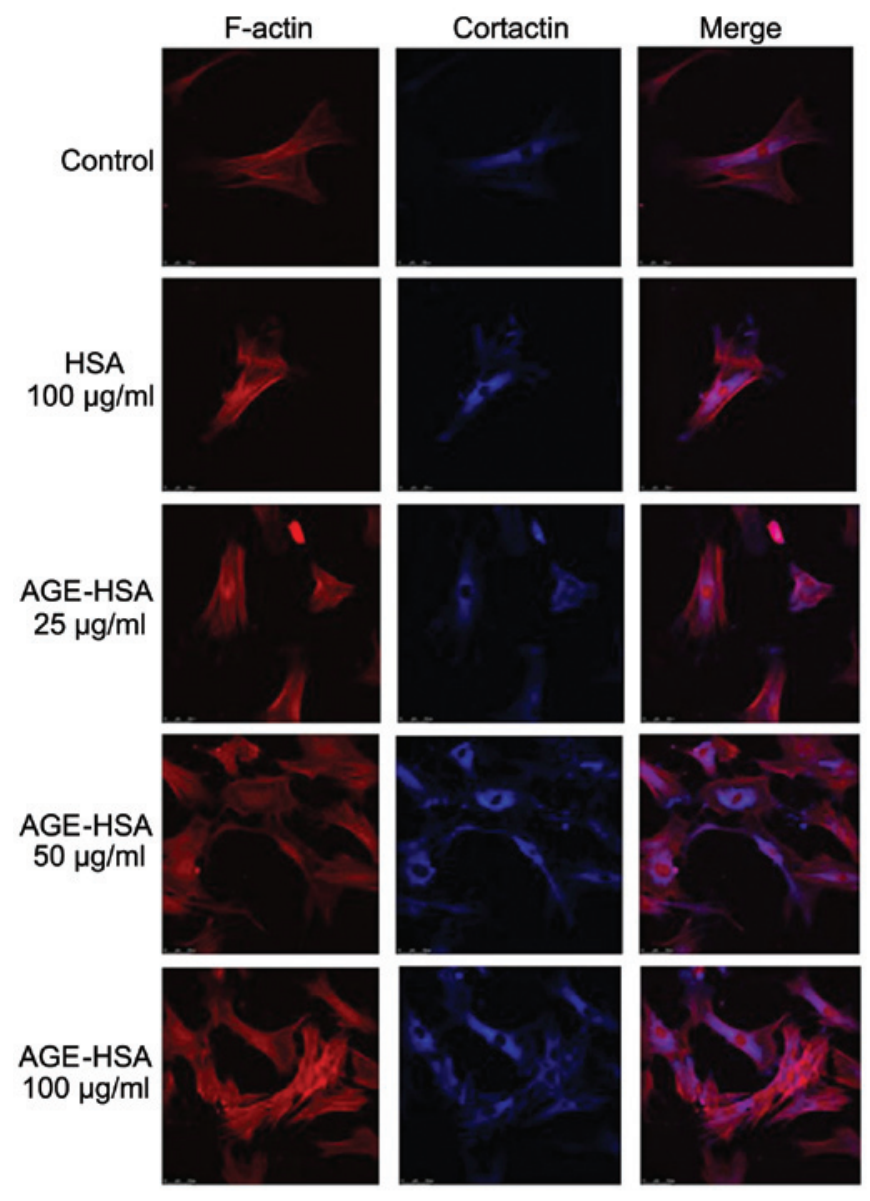

Figure 1. AGE alters the morphology and distribution of F-actin and cortactin in a dose-dependent manner. Rat GECs were treated with different concentrations of AGE-HSA (25, 50 or $100 \mu \mathrm{g} / \mathrm{ml})$ for $8 \mathrm{~h}$. Cells cultured in pure MCDB131 medium (control) or with HSA (100 $\mu \mathrm{g} / \mathrm{ml})$ alone were designated as the controls. With increasing AGE-HAS concentration, the edge of the F-actin peripheral dense band was observed to become rough and irregular with a jagged appearance, F-actin was diffusely distributed in cells and the number of stress fibers increased. Cytoplasmic cortactin was unclear in the cortex and membrane and its distribution became disorganized. AGE, advanced glycation end-products; GEC, glomerular capillary endothelial cells; HSA, human serum albumin.

distributed in the cytoplasm and is occasionally also present in the cell membrane. With an increase in AGE-HSA concentration or treatment time, the edge of the F-actin peripheral dense band was observed to become rough and irregular, with a jagged appearance. F-actin was observed to be diffusely distributed in cells and the number of stress fibers, composed of a single row of non-polar actin filaments, increased. The distribution of cytoplasmic cortactin became disorganized and it was unclear in the cortex and membrane. Cells became round and retracted when treated with AGE-HSA for $8 \mathrm{~h}$ at a concentration of $100 \mu \mathrm{g} / \mathrm{ml}$; however, HSA alone did not produce these effects (Figs. 1 and 2).

Activation of Racl inhibits AGE-HSA-induced morphological alterations to F-actin and cortactin in GECs. The reconfiguration of the structure of F-actin, formation of central stress fibers and retraction in GECs induced by AGE-HSA was markedly inhibited by pre-treatment with O-Me-cAMP. In addition, similar inhibitory effects were observed in

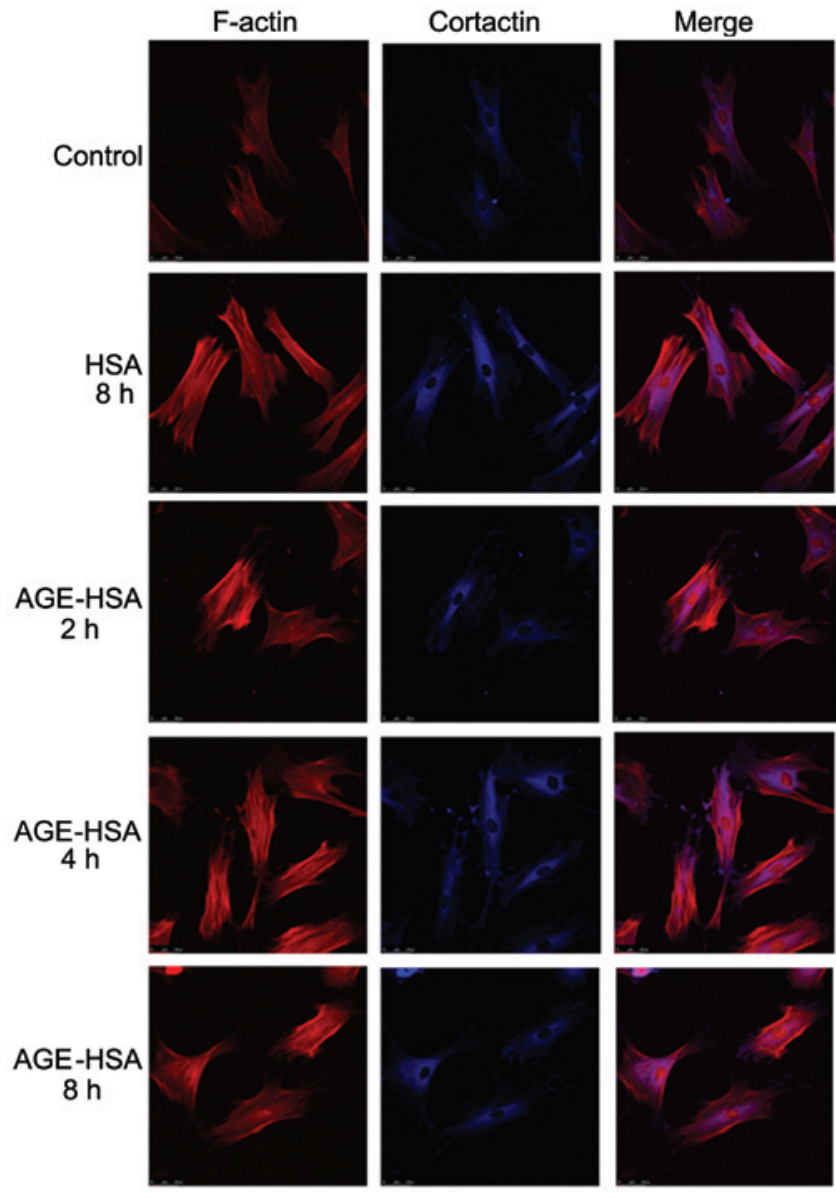

Figure 2. Time-dependent AGE-induced alterations to the morphology and distribution of F-actin and cortactin. GECs were treated with $100 \mu \mathrm{g} / \mathrm{ml}$ AGE-HSA for 2, 4 or $8 \mathrm{~h}$. Cells cultured in pure MCDB131 medium (control) or with HSA $(100 \mu \mathrm{g} / \mathrm{ml})$ alone were designated as the controls. With increasing AGE-HAS treatment time, the edge of the F-actin peripheral dense band was observed to become rough and irregular with a jagged appearance, F-actin was diffusely distributed in cells and the number of stress fibers increased. Cytoplasmic cortactin was unclear in the cortex and membrane and its distribution became disorganized. AGE, advanced glycation end-products; GEC, glomerular capillary endothelial cells; HSA, human serum albumin.

AGE-HSA-induced cortactin disorganization and cell retraction with O-Me-cAMP-pre-treatment. However, HSA alone did not produce this inhibitory effect (Fig. 3). These observations further suggested an involvement of the Racl signaling pathway in the development of AGE-induced morphological and structural alterations in GECs.

Effect of AGE-HSA on the levels of Racl activity in GECs. The levels of Rac1 activity (but not total Racl levels) in the AGE-HSA $(100 \mu \mathrm{g} / \mathrm{ml})$ treatment group were significantly reduced compared with those in the control group $(\mathrm{P}=0.002)$, whereas HSA alone did not produce this effect (Fig. 4). These results suggested that the Rac1 signaling pathway is important in the mediation of AGE-induced functional alterations in endothelial cells.

Racl agonist inhibits the AGE-HSA-induced increase in GEC permeability. The permeability of GECs to FITC-BSA was significantly increased with AGE-HSA-treatment $(\mathrm{P}<0.05)$, 


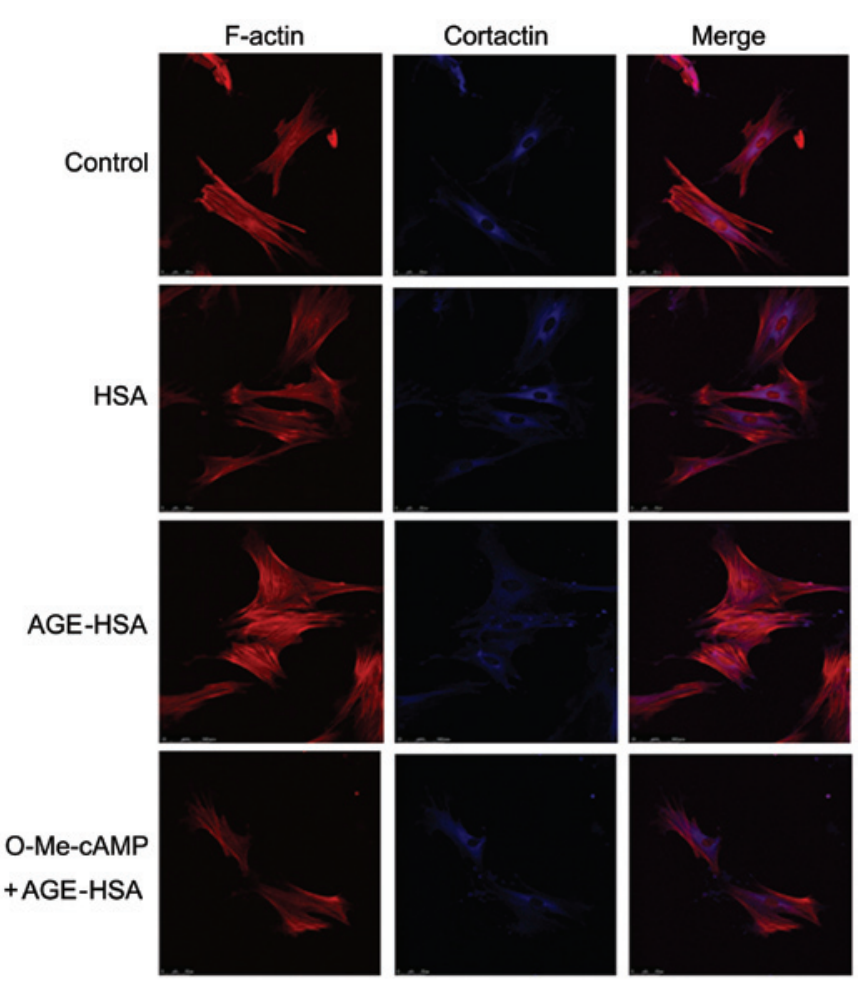

Figure 3. Effect of the Rac1 agonist O-Me-cAMP in regulating AGE-induced alterations in F-actin and cortactin morphology and distribution in endothelial cells. In the O-Me-cAMP group, cells were pre-treated with O-Me-cAMP $(2 \mu \mathrm{mol} / \mathrm{ml})$ for $60 \mathrm{~min}$, then treated with AGE-HSA $(100 \mu \mathrm{g} / \mathrm{ml})$ for $8 \mathrm{~h}$. The cells cultured in pure MCDB131 medium (control) or with HSA $(100 \mu \mathrm{g} / \mathrm{ml})$ alone were designated as the controls. AGE-induced F-actin structure reconstruction, the disorganized distribution of cortactin, altered cell morphology and the formation of stress fibers in endothelial cells were all markedly inhibited by O-Me-cAMP-pre-treatment. O-Me-cAMP, 2'- $O$-methyladenosine-3',5'-cyclic monophosphate; AGE, advanced glycation end-products; GEC, glomerular capillary endothelial cells; HSA, human serum albumin.

but not with HSA alone $(\mathrm{P}>0.05)$. This effect was inhibited by $\mathrm{O}-\mathrm{Me}-\mathrm{AAMP}$, as demonstrated by reduction in $\mathrm{P}_{\mathrm{a}}$ from $189.32 \pm 6.16$ to $128.52 \pm 3.53 \%$ subsequent to treatment with O-Me-cAMP (Fig. 5).

\section{Discussion}

The initial step in the development of diabetes and nephropathy is the structural and functional impairment of GECs, which induces glomerular capillary lesions and leads to disease progression $(31,32)$. The increase in glomerular capillary permeability is considered to indicate the development of diabetes and nephropathy and leads to the development of pathological proteinuria (33). The proximal damage among cells is considered to be the basis for the increase in endothelial cell gap formation and vascular permeability (2,34-36). A number of studies have demonstrated that the alterations in cellular morphology and the distribution of cytoskeletal proteins is closely associated with the integrity of the endothelial cell-cell connections $(37,38)$. The AGE content in diabetic patients has been observed to be significantly increased, which may induce damage to GEC structure and function (39-41). Additional studies have demonstrated that AGE increases the permeability of umbilical vein endothelial cells and induces

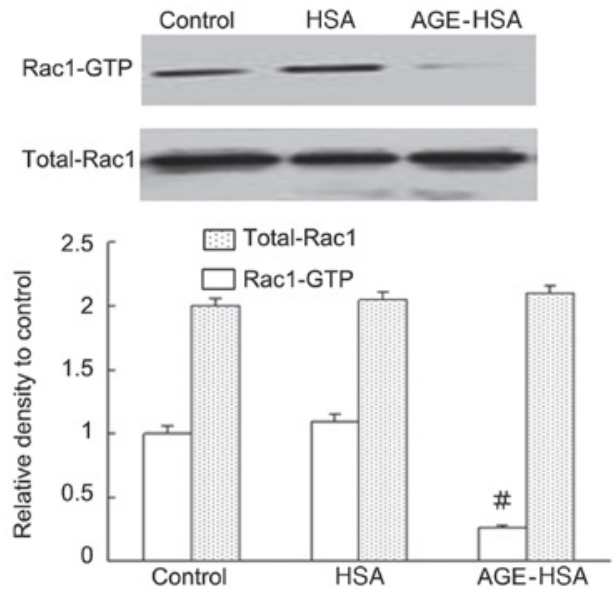

Figure 4. Effect of AGE on the levels of Rac1 activity in GECs. AGE-HSA $(100 \mu \mathrm{g} / \mathrm{ml})$ treatment for $8 \mathrm{~h}$ significantly reduced the levels of Rac1 activity compared with controls, but did not affect the levels of total protein. ${ }^{\#} \mathrm{P}<0.05$ vs. control group. AGE, advanced glycation end-products; GEC, glomerular capillary endothelial cells; HSA, human serum albumin; GTP, guanosine triphosphate.

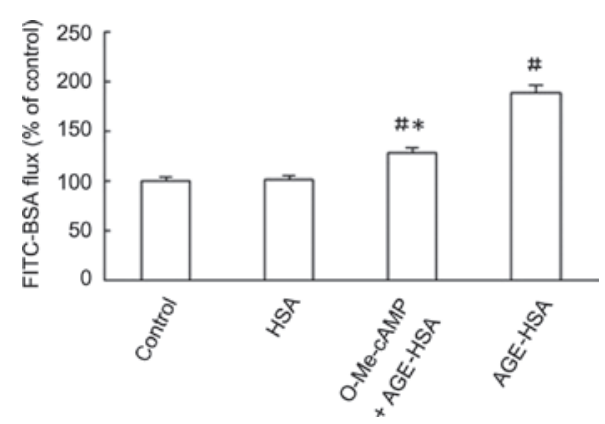

Figure 5. Effect of O-Me-cAMP on mediation of AGE-induced alterations in endothelial cell permeability. Compared with the control group, treatment with AGE-HSA $(100 \mu \mathrm{g} / \mathrm{ml})$ for $8 \mathrm{~h}$ significantly increased permeability in endothelial cells $(\mathrm{P}<0.05)$, which was inhibited by $\mathrm{O}-\mathrm{Me}$-cAMP. " $\mathrm{P}<0.05$ vs. control; ${ }^{*} \mathrm{P}<0.05$ vs. AGE-HSA. O-Me-cAMP, 2'-O-methyladenosine-3',5'-cyclic monophosphate; AGE, advanced glycation end-products; GEC, glomerular capillary endothelial cells; HSA, human serum albumin; BSA, bovine serum albumin.

alterations in the distribution and morphology of cytoskeletal proteins $(8,11,12,14)$. To mimic the pathological process of glomerular capillary endothelial damage in diabetes and nephropathic patients, primary GECs were used in the present study. The effects of AGE on the distribution and morphology of F-actin and cortactin in GECs were investigated and it was determined whether or not these processes were mediated by the Rac1 signaling pathway. Rac1 is a member of the Ras protein superfamily and belongs to the Rho family of guanosine triphosphatases (42). Racl has multiple functions, including controlling cellular morphology, actin movement, transcriptional activation and apoptotic signals (43-46). Rac1 has two active forms, including an active form bound to guanosine triphosphate (GTP) on the cell membrane and an inactive form bound to GTP in the cytoplasm. The two forms can change as a result of upstream stimuli, Rac 1 combining with GTP on the cell membrane is activated, whereas on the cytoplasm it is inactivated, which in turn regulate the functions of downstream effectors. 
It has been demonstrated that Racl can be activated by specific extracellular signals, which in turn induce actin cytoskeleton-directed assembly, resulting in characteristic morphological alterations, including cell stretch (47), an increase in cortical actin polymerization (48) and an enhancement of connections between cells (10). Therefore, the Rac1 signaling pathway is suggested to be necessary for maintaining the stability of vascular endothelial cell connections. Previous studies have suggested that activation of the Rac1 signaling pathway can promote cortactin translocation to the plasma membrane and cortex, thus inhibiting cell collapse and gap-formation and strengthening cell-cell connections (49-51). The mechanism for strengthening these connections is frequently associated with the increase in cortical actin polymerization, cortical cortactin and the enhancement of binding to the cortical actin cytoskeleton. Thus, cortical actin assembly is suggested to be closely associated with cortactin.

In the present study, the observations suggested that the AGE-induced increase in GEC permeability was closely associated with inhibition of Rac1 activity. It was observed that the F-actin peripheral dense band became thicker and disorganized, the number of central stress fibers increased, the expression levels of cortactin in cell membranes were reduced, the boundaries of cells were unclear and cells retracted and deformed upon treatment with AGE in a time- and dose-dependent manner (Figs. 1 and 2). These alterations are associated with the damage to endothelial cell integrity and the increase in permeability. The pull-down assay was used to investigate Racl activity upon treatment with different concentrations of AGE-HSA, and it was observed that AGE-HSA was able to significantly reduce Rac1 activity $(\mathrm{P}<0.05$; Fig. 4$)$. This suggested an important involvement for Racl in the mediation of functional alterations in GECs induced by AGE. In addition, the present study demonstrated that with O-Me-cAMP pre-treatment, AGE-induced alterations in cell morphology and stress fiber-formation (Fig. 3), in addition to increased GEC permeability, were significantly inhibited $(\mathrm{P}<0.05$; Fig. 5).

In conclusion, the results of the present study suggested that Rac1 signaling is important in mediating AGE-induced morphological and functional alterations in GECs. This may aid in the development of novel therapeutic targets for microvascular complications in patients with advanced diabetes. Furthermore, it was observed that O-Me-cAMP was not able to completely reverse AGE-induced alterations, including the disorganization of F-actin and cortactin distribution and morphology, and the increase in cell permeability. This suggested that in addition to the Racl signaling pathway, other pathways may be involved in the pathological processes induced by AGE, which require further investigation.

\section{References}

1. Ying WZ, Lin SY and Qiu CL: Study of permeability of the glomerular capillary wall in human membranous nephropathy. Zhonghua Nei Ke Za Zhi 25: 227-231, 254, 1986 (In Chinese).

2. Satchell SC and Braet F: Glomerular endothelial cell fenestrations: an integral component of the glomerular filtration barrier. Am J Physiol Renal Physiol 296: F947-F956, 2009.

3. Myers BD: Pathophysiology of proteinuria in diabetic glomerular disease. J Hypertens Suppl 8: S41-S46, 1990.

4. Remuzzi G and Bertani T: Is glomerulosclerosis a consequence of altered glomerular permeability to macromolecules? Kidney Int 38: 384-394, 1990
5. Schnoor M, Lai FP, Zarbock A, et al: Cortactin deficiency is associated with reduced neutrophil recruitment but increased vascular permeability in vivo. J Exp Med 208: 1721-1735, 2011.

6. Romero IA, Radewicz K, Jubin E, Michel CC, Greenwood J, Couraud PO and Adamson P: Changes in cytoskeletal and tight junctional proteins correlate with decreased permeability induced by dexamethasone in cultured rat brain endothelial cells. Neurosci Lett 344: 112-116, 2003.

7. Dudek SM and Garcia JG: Cytoskeletal regulation of pulmonary vascular permeability. J Appl Physiol (1985) 91: 1487-1500, 2001.

8. Spindler V, Peter D, Harms GS, Asan E and Waschke J: Ultrastructural analysis reveals cAMP-dependent enhancement of microvascular endothelial barrier functions via Rac1-mediated reorganization of intercellular junctions. Am J Pathol 178: 2424-2436, 2011

9. Peng H, Wang C, Ye ZC, et al: How increased VEGF induces glomerular hyperpermeability: a potential signaling pathway of Rac1 activation. Acta Diabetol 47 (Suppl 1): 57-63, 2010.

10. Spindler V, Schlegel N and Waschke J: Role of GTPases in control of microvascular permeability. Cardiovasc Res 87: 243-253, 2010.

11. Semina EV, Rubina KA, Rutkevich PN, Voyno-Yasenetskaya TA, Parfyonova YV and Tkachuk VA: T-cadherin activates Racl and $\mathrm{Cdc} 42$ and changes endothelial permeability. Biochemistry (Mosc) 74: 362-370, 2009.

12. Mehta D and Malik AB: Signaling mechanisms regulating endothelial permeability. Physiol Rev 86: 279-367, 2006.

13. Guo X, Wang L, Chen B, et al: ERM protein moesin is phosphorylated by advanced glycation end products and modulates endothelial permeability. Am J Physiol Heart Circ Physiol 297: H238-H246, 2009.

14. Guo XH, Huang QB, Chen B, et al: Advanced glycation end products induce actin rearrangement and subsequent hyperpermeability of endothelial cells. APMIS 114: 874-883, 2006.

15. Guo XH, Huang QB, Chen B, Wang SY, Hou FF and Fu N: Mechanism of advanced glycation end products-induced hyperpermeability in endothelial cells. Sheng Li Xue Bao 57: 205-210, 2005 (In Chinese).

16. Sheikpranbabu S, Haribalaganesh R, Lee KJ and Gurunathan S: Pigment epithelium-derived factor inhibits advanced glycation end products-induced retinal vascular permeability. Biochimie 92: 1040-1051, 2010.

17. Akis $\mathrm{N}$ and Madaio MP: Isolation, culture, and characterization of endothelial cells from mouse glomeruli. Kidney Int 65: 2223-2227, 2004.

18. Rops AL, van der Vlag J, Jacobs CW, et al: Isolation and characterization of conditionally immortalized mouse glomerular endothelial cell lines. Kidney Int 66: 2193-2201, 2004

19. Laulajainen T, Julkunen I, Haltia A, Knuutila S, Miettinen A and Holthöfer $\mathrm{H}$ : Establishment and characterization of a rat glomerular endothelial cell line. Lab Invest 69: 183-192, 1993.

20. Glomb MA and Monnier VM: Mechanism of protein modification by glyoxal and glycolaldehyde, reactive intermediates of the Maillard reaction. J Biol Chem 270: 10017-10026, 1995.

21. Nagai R, Unno Y, Hayashi MC, Masuda S, Hayase F, Kinae $\mathrm{N}$ and Horiuchi S: Peroxynitrite induces formation of $\mathrm{N}$ ( epsilon )-(carboxymethyl) lysine by the cleavage of Amadori product and generation of glucosone and glyoxal from glucose: novel pathways for protein modification by peroxynitrite. Diabetes 51: 2833-2839, 2002.

22. Hou FF, Boyce J, Chertow GM, Kay J and Owen WF Jr: Aminoguanidine inhibits advanced glycation end products formation on beta2-microglobulin. J Am Soc Nephrol 9: 277-283, 1998.

23. Hou FF, Miyata T, Boyce J, et al: beta(2)-Microglobulin modified with advanced glycation end products delays monocyte apoptosis. Kidney Int 59: 990-1002, 2001.

24. Eiselein L, Wilson DW, Lamé MW and Rutledge JC: Lipolysis products from triglyceride-rich lipoproteins increase endothelial permeability, perturb zonula occludens- 1 and F-actin, and induce apoptosis. Am J Physiol Heart Circ Physiol 292: H2745-H2753, 2007.

25. Zheng HZ, Zhao KS, Zhou BY and Huang QB: Role of Rho kinase and actin filament in the increased vascular permeability of skin venules in rats after scalding. Burns 29: 820-827, 2003.

26. Wu H and Parsons JT: Cortactin, an 80/85-kilodalton pp60sre substrate, is a filamentous actin-binding protein enriched in the cell cortex. J Cell Biol 120: 1417-1426, 1993. 
27. Paradis H, Islam T, Tucker S, Tao L, Koubi S and Gendron RL: Tubedown associates with cortactin and controls permeability of retinal endothelial cells to albumin. J Cell Sci 121: 1965-1972, 2008

28. Ando $\mathrm{K}$, Ishibashi $\mathrm{T}$, Ohkawara $\mathrm{H}$, et al: Crucial role of membrane type 1 matrix metalloproteinase (MT1- MMP) in RhoA/Rac1-dependent signaling pathways in thrombin- stimulated endothelial cells. J Atheroscler Thromb 18: 762-773, 2011.

29. Boutoille D, Marechal X, Pichenot M, Chemani C, Guery B and Faure K: FITC-albumin as a marker for assessment of endothelial permeability in mice: comparison with 125I-albumin. Exp Lung Res 35: 263-271, 2009.

30. Kajiya M,Komatsuzawa H,Papantonakis A, et al: Aggregatibacter actinomycetemcomitans Omp29 is associated with bacteria entry to gingival epithelial cells by F-actin rearrangement. PLoS One 6: e18287, 2011

31. Swärd P and Rippe B: Acute and sustained actions of hyperglycaemia on endothelial and glomerular barrier permeability. Acta Physiol (Oxf) 204: 294-307, 2012.

32. Balakumar P, Chakkarwar VA, Krishan P and Singh M: Vascular endothelial dysfunction: a tug of war in diabetic nephropathy? Biomed Pharmacother 63: 171-179, 2009.

33. Thomas MC: Pathogenesis and progression of proteinuria. Contrib Nephrol 170: 48-56, 2011.

34. Dane MJ, van den Berg BM, Avramut MC, et al: Glomerular endothelial surface layer acts as a barrier against albumin filtration. Am J Pathol 82: 1532-1540, 2013.

35. Stewart RJ and Marsden PA: Vascular endothelial cell activation in models of vascular and glomerular injury. Kidney Int Suppl 45: S37-S44, 1994

36. Koike K, Aiboshi J, Shinozawa Y, Sekine K, Endo T and Yamamoto Y: Correlation of glomerular permeability, endothelial injury, and postoperative multiple organ dysfunction. Surg Today 34: 811-816, 2004

37. Bates DO: Vascular endothelial growth factors and vascular permeability. Cardiovasc Res 87: 262-271, 2010.

38. Bogatcheva NV and Verin AD: The role of cytoskeleton in the regulation of vascular endothelial barrier function. Microvasc Res 76: 202-207, 2008.

39. Soulis T, Thallas V, Youssef S, et al: Advanced glycation end products and their receptors co-localise in rat organs susceptible to diabetic microvascular injury. Diabetologia 40: 619-628, 1997.
40. Hori O, Yan SD, Ogawa S, Kuwabara K, Matsumoto M, Stern D and Schmidt AM: The receptor for advanced glycation end-products has a central role in mediating the effects of advanced glycation end-products on the development of vascular disease in diabetes mellitus. Nephrol Dial Transplant 11 (Suppl 5): 13-16, 1996.

41. Yamagishi S: Role of advanced glycation end products (AGEs) and receptor for AGEs (RAGE) in vascular damage in diabetes. Exp Gerontol 46: 217-224, 2011.

42. Bond M, Wu YJ, Sala-Newby GB and Newby AC: Rho GTPase, Rac1, regulates Skp2 levels, vascular smooth muscle cell proliferation, and intima formation in vitro and in vivo. Cardiovase Res 80: 290-298, 2008.

43. Szczepanowska J: Involvement of Rac/Cdc42/PAK pathway in cytoskeletal rearrangements. Acta Biochim Pol 56: 225-234, 2009.

44. Pai SY, Kim C and Williams DA: Rac GTPases in human diseases. Dis Markers 29: 177-187, 2010.

45. Williams LM, Lali F, Willetts K, et al: Rac mediates TNF-induced cytokine production via modulation of NF-kappaB. Mol Immunol 45: 2446-2454, 2008.

46. Mondal S, Ghosh-Roy S, Loison F, et al: PTEN negatively regulates engulfment of apoptotic cells by modulating activation of Rac GTPase. J Immunol 187: 5783-5794, 2011.

47. Chang F, Lemmon C, Lietha D, Eck M and Romer L: Tyrosine phosphorylation of Rac1: a role in regulation of cell spreading. PLoS One 6: e28587, 2011.

48. Jacobson JR, Dudek SM, Singleton PA, Kolosova IA, Verin AD and Garcia JG: Endothelial cell barrier enhancement by ATP is mediated by the small GTPase Rac and cortactin. Am J Physiol Lung Cell Mol Physiol 291: L289-L295, 2006.

49. Weed SA, Du Y and Parsons JT: Translocation of cortactin to the cell periphery is mediated by the small GTPase Racl. J Cell Sci 111: 2433-2443, 1998

50. Adamson RH, Sarai RK, Altangerel A, Thirkill TL, Clark JF and Curry FR: Sphingosine-1-phosphate modulation of basal permeability and acute inflammatory responses in rat venular microvessels. Cardiovasc Res 88: 344-351, 2010.

51. Maharjan S, Kim K, Agrawal V, et al: Sac-1004, a novel vascular leakage blocker, enhances endothelial barrier through the cAMP/Rac/cortactin pathway. Biochem Biophys Res Commun 435: 420-427, 2013. 